\title{
Design Development of Blast freezer
}

\author{
Dr. Raju N. Panchal ${ }^{1}$, Ganesh S. Jadhav ${ }^{2}$, Gurunath Shinde ${ }^{3}$, Sonali V. Dhatunde ${ }^{4}$, Nutan J. Nikam ${ }^{5}$, \\ Pritee H. Mane ${ }^{6}$ \\ Professor and HOD, Department of Mechanical Engineering, AGTI'S DACOE, Karad, India ${ }^{1}$ \\ Assistant Professor, Department of Mechanical Engineering, AGTI'S DACOE, Karad, India ${ }^{2,3}$ \\ Product Engineer (R\&D) Emerson Climate Technologies, Karad, India ${ }^{4}$ \\ Graduate Student, Department of Mechanical Engineering, AGTI'S DACOE, Karad, India ${ }^{5,6}$
}

\begin{abstract}
The experimental set up of Cold room, at Dattwad, Tal- Shirol, Dist- Kolhapur (Near Narsobachi Wadi) on prepared model of cold storage, The compressor, condenser unit, evaporation unit, expansion valve are used and special experimental cold storage box is attached with refrigeration system, the device, thermo couple are attached with this cooling unit here the design experiments is based on Air Cooling system. In this paper we are designing the cold storage plant which is maintaining at $-25^{\circ} \mathrm{C}$. At this temperature all types of foods are stored liked fruits, ice-creams and all dairy products. In this work our main objective is to Optimum insulation thickness, Area of wall, compressor capacity of cold storage. Also this project deals with different aspects of design of cold storage and includes all standard refrigeration principles and heat load factors which are normally considered in a cold storage design.
\end{abstract}

Keywords: Blast Freezer, Design, Refrigeration, Cold-Storage.

\section{INTRODUCTION}

This document is a template. An electronic copy can be downloaded from the conference website. For questions on paper guidelines, please contact the conference publications co The cold storage is building designed to stored certain goods like food stuffs, fruits, vegetables, dairy products within well defined temperature range and relative humidity $(\mathrm{RH})$. Cold storage is also an application of air conditioning in a way that the air is cooled by passing it over a cooling of refrigeration plant and supplied back to the room.

The temperature and humidity conditions maintained inside the cold storage The maximum storage period for long term storage ranges from seven to ten days for some sensitive product like ripe tomatoes \& up to six or eight months for more durable products such as onions \& smoked meat.

When perishable foods are to be stored for long period, they should be frozen and stored in frozen storages. However, some fresh foods like tomatoes are damaged by freezing process and therefore cannot be successfully frozen.

In general, the conditions required for short term storage are more flexible than those required for long term storage and higher storage temperatures are permissible for short term storage.

Thus the conditions required for the storage can be divided in to two categories.

a) Cold storages for products which are to be maintained at temperature of ${ }^{\circ} \mathrm{C}$ and $0^{\circ} \mathrm{C}$ above

b) Cold storages for products which are to be maintained at temperature below $0^{\circ} \mathrm{C}$.
It may be noted that the refrigeration does not improve the quality of the food products if only slows down its deterioration. The product must be under refrigeration for the entire course of the passage from the producer to the consumer and this continuity is known as the cold chain.

During storage the vegetables and fruits produce heat of respiration. Thus the refrigeration plant must be designed to take care of this load in addition to the usual heat loads.

a) Cold storages for products which are to be maintained at temperature of ${ }^{\circ} \mathrm{C}$ and $0^{\circ} \mathrm{C}$ above

b) Cold storages for products which are to be maintained at temperature below $0^{\circ} \mathrm{C}$.

It may be noted that the refrigeration does not improve the quality of the food products if only slows down its deterioration. The product must be under refrigeration for the entire course of the passage from the producer to the consumer and this continuity is known as the cold chain.

During storage the vegetables and fruits produce heat of respiration. Thus the refrigeration plant must be designed to take care of this load in addition to the usual heat loads.

\section{BASICS OF REFRIGERATION}

Refrigeration is a process of moving heat from one location to another in controlled conditions. The work of heat transport is traditionally driven by mechanical work, but can also be driven by heat, magnetism, electricity, laser, or other means. Refrigeration has many applications including, but not limited to: household refrigerators, industrial freezers, cryogenics, and air conditioning. Heat pumps may use the heat output of the refrigeration 
IAR JSET

International Advanced Research Journal in Science, Engineering and Technology

National Conference on Design, Manufacturing, Energy \& Thermal Engineering (NCDMETE-2017)

AGTI's Dr. Daulatrao Aher College Engineering, Vidyanagar Extension, Karad

Vol. 4, Special Issue 1, January 2017

process, and also may be designed to be reversible, but are otherwise similar to refrigeration units.

A refrigeration system utilizes work supplied by an electric motor to transfer heat from a space to be cooled to a high temperature sink (place to be heated). Low temperature boiling fluids called refrigerants absorb thermal energy to get vaporized in the evaporator causing a cooling effect in the region being cooled. While comparing the advantages and disadvantages of various cooling systems, two most important parameters i.e the operating temperature and the coefficient of performance are of vital importance in these systems. These systems can be evaluated using energy and energy analyses which are based on first and second law of thermodynamics, respectively.

Vapour Compression Refrigeration Systems.

Vapour-compression refrigeration or Vapour-compression refrigeration system (VCRS), in which the refrigerant undergoes phase changes, is one of the many refrigeration cycles and is the most widely used method for air-conditioning of buildings and automobiles. It is also used in domestic and commercial refrigerators, large-scale warehouses for chilled or frozen storage of foods and meats, refrigerated trucks and railroad cars, and a host of other commercial and industrial services. Oil refineries, petrochemical and chemical processing plants, and natural gas processing plants are among the many types of industrial plants that often utilize large vapourcompression refrigeration systems.

Refrigeration may be defined as lowering the temperature of an enclosed space by removing heat from that space and transferring it elsewhere. A device that performs this function may also be called an air conditioner, refrigerator, air source heat pump, geothermal heat pump or chiller (heat pump).The salient components of vapour compression refrigeration system used in Indian cold storage system are: evaporator, compressor, condenser and manually operated expansion valve. A typical schematic diagram of the refrigeration system is shown below in figure.

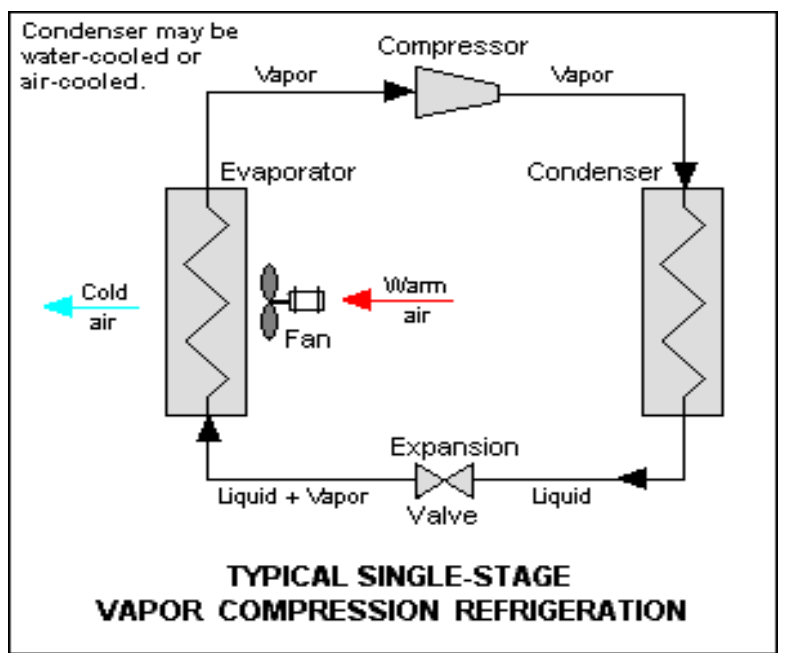

Classification of cold storage:

General

A typical cold storage system can be divided into:

a) General cold store (commercial and industrial)

b) Freezing storage system.

c) Pre-fabricated cold stores

Product category:

Generally classified by ASHRAE as follows.

Class 1:

Include products which require very high relative humidities in order to minimize moisture loss during storage. Examples of this category include unpackaged cheese or butter, eggs, and most vegetables if held for comparatively long periods.

Class 2:

Include products which require reasonably high relative humidities (but not as high as those included in class 1). Examples of this category include fruits, cut meats in retail storage. (Some supermarket fixtures for cut meat display may be designed to operate with lower temperature difference.)

Class 3:

Include products which require only moderate relative humidities, and includes such products as mushrooms, carcass meats, hides, smoked fish, and fruits such as melons having tough skins.

Class 4:

Include products which are either unaffected by humidity, or which require specialized storage conditions in which the maximum relative humidity is limited through use of a reheat system. Examples of the first group are furs, woolens, milk, bottled beverages, canned goods and similar products having a protective coating; nuts and chocolates are good examples of the second group.

Cooling Load Calculations:

The total heat required to be removed from the space in order to bring it at the desired temperature by the air conditioning and refrigeration equipment ia known as cooling load.

The purpose of load estimation is to determine the size of the air conditioning and refrigeration equipment that is required to maintain inside design conditions during periods of maximum outside temperatures. The design load is based on inside and outside design conditions and it is air conditioning and refrigeration capacity to produce and maintain satisfactory inside conditions.

\section{COOLING LOADS CLASSIFIED BY SOURCE}

Heat transfer through the building skin by conduction Solar heat gains (radiation) through glass or Other transparent materials Heat gains from ventilation air / infiltration of outside air Internal heat gains generated by occupants, lights, appliances, \& machinery. 
IARJSET

\section{COOLING LOAD CLASSIFIED BY KINDS OF} HEAT

There are two components of air conditioning load

1. Sensible load (heat gain)

2. Latent load (water vapour gain)

- SENSIBLE LOADS:

Sensible heat gain is the direct addition of heat to a space, which results in increase of space temperature.

1) Solar heat gain through building envelop ( Exterior walls, glazing, skylights, roofs, floors over crawl space)

2) Partitions

3) Ventilation air and air infiltration through cracks in the building, doors, and windows.

4) People in the building

5) Equipment and appliances in the summer

6) Lights

\section{- LATENT LOADS :}

A latent heat gain is the heat contained in water vapour. It is the heat that must be removed to condense the moisture out of the air.

1) People breathing

2) Cooking equipment

3) Appliances

4) Ventilation air and air infiltration

- Units of Heat :

- British thermal unit in British system

- Calorie in Metric System

- British thermal unit :

It is defined as the energy required to raise or lower 1 degree $\mathrm{F}$ of temperature of 1 pound of water or ice.

$12,000 \mathrm{BTU} / \mathrm{hr}=1 \mathrm{TR}$

Equations

1. $\mathrm{RSH}+\mathrm{RLH}=\mathrm{RTH}$

2. $\mathrm{RSHF}=\mathrm{RSH} / \mathrm{RTH}$

3. $\mathrm{RSH}+$ By pass Air Load Sensible $=\mathrm{ERSH}$

4. $\mathrm{RLH}+\mathrm{By}$ pass Air Load Latent $=\mathrm{ERLH}$

5. $\mathrm{ERSH}+\mathrm{ERLH}=\mathrm{ERTH}$

6. $\mathrm{ERSHF}=\mathrm{ERSH} / \mathrm{ERTH}$

7. ERTH + Outside Air Heat Load + Heat gain in fan, motor, pump $=$ Grand Total Heat.

\section{CONCLUSION}

It is concluded that while designing the cold storage plant which is maintaining at $-25^{\circ} \mathrm{C}$. At this temperature all types of foods are stored liked fruits, ice-creams and all dairy products. In this work our main objective is to Optimum insulation thickness, Area of wall, compressor capacity of cold storage. This design deals with different aspects of design of cold storage and includes all standard refrigeration principles and heat load factors which are normally considered in a cold storage design.

\section{ACKNOWLEDGMENT}

We are especially thankful to all managers, engineers and workers of Cold room, at Dattwad, Tal- Shirol, DistKolhapur company who were involved during carrying out this work. We are also thankful to Dr.Daulatrao Aher College of Engineering Karad.

\section{REFERENCES}

1) Patel Amit M., Patel R. I., Optimization of different parameter of cold storage for energy conservation, International Journal of Modern Engineering Research, Vol.2, Issue.3, May-June 2012 pp1001-1005

2) IPEBS Heating Ventilation and Air Conditioning (HVAC) Manual - Institute of Piping Engg \& Building Services. ASHRAE Handbook of refrigeration. WWW.IPEBS.IN

3) Patel Amit M., Patel R. I., Optimization of different parameter of cold storage for energy conservation, International Journal of Modern Engineering Research, Vol.2, Issue.3, May-June 2012 pp1001-1005.

4) Patel Amit M., Patel R. I., Optimization of different parameter of cold storage for energy conservation, International Journal of Modern Engineering Research, Vol.2, Issue.3, May-June 2012 pp1001-1005.

5) IPEBS Heating Ventilation and Air Conditioning (HVAC) Manual - Institute of Piping Engg \& Building Services. ASHRAE Handbook of refrigeration. WWW.IPEBS.IN

6) IPEBS Heating Ventilation and Air Conditioning (HVAC) Manual - Institute of Piping Engg \& Building Services. ASHRAE Handbook of refrigeration. WWW.IPEBS.IN

7) IPEBS Heating Ventilation and Air Conditioning (HVAC) Manual - Institute of Piping Engg \& Building Services. ASHRAE Handbook of refrigeration. WWW.IPEBS.IN

8) IPEBS Heating Ventilation and Air Conditioning (HVAC) Manual - Institute of Piping Engg \& Building Services. ASHRAE Handbook of refrigeration. WWW.IPEBS.IN

9) IPEBS Heating Ventilation and Air Conditioning (HVAC) Manual - Institute of Piping Engg \& Building Services. ASHRAE Handbook of refrigeration. WWW.IPEBS.IN

10) ISHRAE Handbook of Refrigeration- Cold Storage Basics by Arvind Surange 